\title{
Correlation and Heritability Studies of Yield and Yield Related Traits in F5 Triticum aestivum Lines from a Cross Cv Fsd-08 $\times$ Cv S-24
}

Shehrooz Afzal ${ }^{* *}$, Misbah Amir ${ }^{1}$, Sanobar Shadab Qamar ${ }^{1}$, Ayesha Tariq ${ }^{1}$, Muhammad Javed ${ }^{1,2}$, Zafar Ullah Zafar ${ }^{1}$ and Habib ur Rehman Athar ${ }^{1 *}$

${ }^{1}$ Institute of Pure and Applied Biology, Bahauddin Zakariya University, Multan, Pakistan

${ }^{2}$ Department of Botany, Division of Science and Technology, University of Education, Lahore, Pakistan

\section{Article history:}

Received: 28 Oct., 2021

Revised: 27 Nov., 2021

Accepted: 29 Dec., 2021

\section{Citation:}

Afzal S, M Amir, SS Qamar, A Tariq, M Javed, ZU Zafar and H ur R Athar. 2021. Correlation and Heritability Studies of Yield and Yield Related Traits in F5 Triticum aestivum Lines from a Cross Cv Fsd-08 $\times$ Cv S-24. Journal of Cereal Research 13(3): 287-294. http://doi. org/10.25174/2582-2675/2022/119710

\section{*Corresponding author:}

E-mail: shehroozafzal605@gmail.com

(C) Society for Advancement of Wheat and Barley Research

\begin{abstract}
The heritability estimates give information about traits which are transferred from one generation to another generation, and it has important role in selection criteria to enhance the yield potential. The purpose of current study was to estimate heritability and genetic advance of $\mathbf{F}_{5}$ wheat lines derived from a cross of Faisalabad 2008 and S-24. Eight yield parameters were evaluated during the year 2019-20 in complete randomize design with five replicates. The results of ANOVA showed significant difference $(P \leq 0.001)$ in all studied traits. High broad sense heritability was observed for grain yield per spike $(82.49 \%)$ followed by tillers per plant $(81.77 \%)$ and spikelet per spike (76.65\%). Moderate to low genetic advance was observed for all the traits except plant height (79.47\%), and grain yield per spike have $73.10 \%$. Grain yield have positive correlation with fertile tiller, 100 seed weight and grain yield per spike. The traits grain yield per spike, tillers per plant and spikelet per spike deserve more attention in future breeding programs for evolving better wheat yield.
\end{abstract}

Key words: Broad sense heritability, GCV, Genetic advance, PCV, Wheat

\section{Introduction}

Wheat (Triticum aestivum L.) is a major cereal crop all over the world as major contributor to human diet and rich in energy so called king of cereals. It provides 36 percent food and shares 20 percent food calories to the population throughout world (Tabinda and Bharadwaj, 2015). Generally, Asia is the principal contributor in wheat production and produce approximately 40 percent of overall wheat production that is near about 292.5 million tones as compared to the global production that is approximately 653.6 million tones. In Asia, China is major contributor of the wheat that produces approximately 115.5 million tones followed by India and Pakistan (Gianessi, 2014). On the other hand, average hectare ${ }^{-1}$ wheat production in Pakistan is very low as comparison to other countries (Fao, 2008). The FCA (Federal Committee on Agriculture) fixed wheat production target at 28.9 million tons, expecting a sowing area of 9.2 million hectares for the Rabi season 2021 to 22, an increase of 1.4 million tons over last year's production (DAWN, October 8, 2021).

For a successful plant breeding program, the genetic variations present in breeding material used in the program has primary importance. The observed difference is combination of genetic and environmental factors. The successful selection depends on genetic divergence, heritability estimates and association of agro- 
morphological traits with grain production. The estimates of heritability along with correlation studies offer a better consideration of the association of important traits with grain yield (Ali et al., 2008).

The improvement of crop relies on genetics during various breeding programs. The Higher ratio of Ve (environmental variance) lower will be the chance to choose the genetic variations. Similarly, the selection rate will rise when ration of difference due to environmental factors is lower than genetic variability (Ali et al., 2017). Therefore it is suggested to be appropriate knowledge about heritability and selection reply for essential yield linked traits during crop enhancement programs (Waqar-Ul-Haq et al., 2008). The traits having high heritability could be choose during breeding programs that will make easier progress to those traits having low heritability estimates (Shahid et al., 2002).

Grain yield is the most important polygenetic trait in cereal crops which is not only affected by external environment but also depends upon other yield related traits. Therefore, our selection should not be directly based upon grain yield, but focus should also be given to other yield related traits. Besides the knowledge of Grain yield is the most important polygenetic trait in cereal crops which is not only affected by external environment but also depends upon other yield related traits. Therefore, our selection should not be directly based upon grain yield, but focus should also be given to other yield related traits (Akhtar and Chowdhary, 2006; Majumder et al., 2008, Kumar et al. 2019).

Present study was conducted to explore genetic variability, heritability and correlation among wheat advanced lines using eight yield related traits to devise selection criteria for isolation of best performing lines.

\section{Materials and Methods}

The data was recorded for the year 2019-2020. The seeds of $\mathrm{F}_{5}$ progeny and their parent varieties Faisalabad 2008 and S-24 were obtained to conduct the research. The experiment was carried out in complete randomized block design having 5 replicates. The distance between lines were kept $12 \mathrm{~cm}$. The recommended dose of nitrogen and phosphorus were used before and after sowing the crop. Weeds were removed manually as and when required.

At maturity 5 plants were selected at random from each line in each replication for recording data on six quantitative traits including plant height, number of productive tillers per plant, number of spikelets per spike, spike length, number of grains per spike, 100 grain weight (g) and yield per plant (g).

The mean data was subjected to analysis of variance to test the level of significance among the parent genotypes and $\mathrm{F}_{5}$ progeny (Steel and Torrie, 1980).

The broad sense heritability was calculated as a ratio of genotypic to phenotypic variance. The expected genetic advances estimated. The genotypic and phenotypic coefficients of variations were calculated for the estimation of variability (Falconer, 1996).

$\mathbf{h}^{2} \mathbf{B}=\mathrm{Vg} / \mathrm{Vp}$

where,

$\mathbf{V g}=$ genotypic variance

$\mathbf{V p}=$ phenotypic variance

\section{Genetic Advance $(\mathbf{G A})=\mathbf{K} \times(\mathbf{V} \mathbf{p})^{0.5} \times \mathbf{h}^{2} \mathbf{B}$}

where,

$\mathrm{K}=$ selection intensity at 5\% (2.06)

$\mathrm{Vp}=$ phenotypic variance

$\mathrm{h}^{2} \mathrm{~B}=$ heritability (broad sense)

$$
\mathbf{G A}(\%)=\mathbf{G A} / \mathbf{G A M} \times \mathbf{1 0 0}
$$

$\mathrm{GA}=$ Genetic advance

$\mathrm{GAM}=$ Genetic advance Mean

Phenotypic Coefficient of Variation $(\mathrm{PCV})=$

Phenotypic Variance (Vp) / Mean value of the trait $\times 100$

Genotypic Coefficient of Variation $(\mathrm{GCV})=$

Genotypic Variance (Vg) / Mean value of the trait $\times 100$

\section{Results and Discussion}

Plant height is one of the important characters that determine the yield along with other characters. The short stature of wheat plants was responsible for the green revolution. Short stature plants are desirable in wheat to obtain more yield per acre. Higher plants generally considered as a source of substantial amount of straw which has not much importance. The mean square depicts highly significant variation among the genotypes for plant height (Table 1). The mean value for plant height $(\mathrm{cm})$ of wheat from 63.55 to $94.80 \mathrm{~cm}$ (Table 2). The phenotypic coefficient of variance and genotypic coefficient of variance for plant height was $9.33 \%$ and $5.56 \%$ respectively. The 
broad-sense heritability percentage for plant height was $35.57 \%$ and the genetic advance percentage was $79.47 \%$ (Table 3 ). In the present data, low heritability with high genetic advance was observed. The broad sense heritability for plant height is $35.57 \%$ which means this trait is less heritable than other traits. Jocković et al. (2013) observed low heritability estimates in Helianthus annuus L. Kamboj (2003), Sial (2007), Khan and Naqvi (2011) who reported high heritability and low genetic advance for plant height for wheat.

Table 1. Mean square values for plant height, spike length, spikelet spike ${ }^{-1}$, total tillers, fertile tillers, total seed weight, 100 seed weight, yield spike ${ }^{-1}$ of F5 wheat lines.

\begin{tabular}{cccccc}
\hline SOV & df & Plant Height $(\mathbf{c m})$ & Spike Length $(\mathbf{c m})$ & Spikelet per spike & Tillers per Plant \\
\hline Lines & 103 & $460.146^{* * *}$ & $5.639^{* * *}$ & $22.322^{* * *}$ & $12.00^{* * *}$ \\
Error & 416 & 27.4681 & 1.007 & 2.553 & 3.890 \\
SOV & df & Fertile Tillers & Total Seed Weight & $\mathbf{1 0 0 ~ S e e d ~ W e i g h t ~}$ & Total Yield Spike ${ }^{-1}$ \\
Lines & 103 & $15.427^{* * *}$ & $48.915^{* * *}$ & $1.339^{* * *}$ & $0.472^{* * *}$ \\
Error & 416 & 6.1173 & 12.658 & 0.752 & 0.246 \\
Total & 519 & & & &
\end{tabular}

Table 2. Estimation of heritability and genetic advance (\%) for yield and yield related traits in F5 lines of wheat.

\begin{tabular}{lccccccc}
\hline \multicolumn{1}{c}{ Parameters } & Mean & Min. & Max. & PCV\% & GCV\% & H $^{2} \mathbf{b}$ & GA $\%$ \\
\hline Plant Height & 79.47 & 63.55 & 94.80 & 9.33 & 5.56 & 35.57 & 79.47 \\
Spike Length & 10.94 & 9.30 & 13.18 & 11.51 & 4.62 & 7.29 & 10.94 \\
Spikelet/Spike & 20.11 & 14.23 & 24.34 & 10.71 & 9.38 & 76.65 & 20.12 \\
Total Tillers & 7.25 & 4.4 & 11.5 & 20 & 18.09 & 81.77 & 10.75 \\
Fertile Tillers & 10.76 & 6.2 & 13.4 & 35.43 & 20.18 & 32.43 & 7.25 \\
Total Seed Weight (g) & 9.81 & 4.31 & 20.26 & 35.03 & 17.17 & 24.01 & 9.81 \\
100 Seed Weight (g) & 4.06 & 3.06 & 5.19 & 15.39 & 7.85 & 25.97 & 33.48 \\
Yield/Spike(g) & 0.98 & 0.50 & 2.27 & 43.84 & 39.81 & 82.49 & 73.10 \\
\hline
\end{tabular}

Table 3. Phenotypic correlation coefficients of yield and yield related traits

\begin{tabular}{|c|c|c|c|c|c|c|c|c|}
\hline Traits & $\mathbf{P H}$ & SL & SS & TPP & FTP & GYP & HSW & GYS $^{1}$ \\
\hline $\mathbf{P H}$ & 1 & & & & & & & \\
\hline SL & $0.4073^{* * * *}$ & 1 & & & & & & \\
\hline SS & $0.3685^{* * *}$ & $0.1252 * *$ & 1 & & & & & \\
\hline TPP & $0.2602 * * *$ & $0.1947 * * *$ & $0.0137^{\mathrm{ns}}$ & 1 & & & & \\
\hline FTP & $0.1129 * *$ & $0.1063^{*}$ & $0.0053^{\mathrm{ns}}$ & $0.5056^{* * *}$ & 1 & & & \\
\hline $\mathbf{G Y P}^{1}$ & $0.0468^{\mathrm{ns}}$ & $-0.0035^{\mathrm{ns}}$ & $0.1199 * *$ & $-0.0137^{\mathrm{ns}}$ & $0.0699^{\text {ns }}$ & 1 & & \\
\hline HSW & $-0.1007 *$ & $0.0123^{\text {ns }}$ & $-0.0345^{\mathrm{ns}}$ & $0.0457^{\mathrm{ns}}$ & $0.1754 * * *$ & $0.1561 * * *$ & 1 & \\
\hline GYS $^{1}$ & $0.1558 * * *$ & $0.0691^{\mathrm{ns}}$ & $0.1097^{*}$ & $0.0302^{\mathrm{ns}}$ & $0.0568^{\mathrm{ns}}$ & $0.3587^{* * *}$ & $0.1102 *$ & 1 \\
\hline
\end{tabular}

PH: Plant height; SL: Spike length; SS: Spikelet spike; TPP: Tillers per plant; FTP: Fertile tiller per plant; GYP: Grain per plant; GYP: Grain yield per plant; HSW: Hundred seed weight; GPS: Grains per spike; ns $=$ non-significant; ${ }^{*}, * * * * *=0.05,0.01,0.001$ levels respectively. 
Spike length is another important trait, as large spikes are likely to produce more grains which lead to more yield per plant. Higher phenotypic coefficient of variability compared to genotypic is indicative of more environmental influence. Mean square analysis of variance showed significant difference for spike length (Table I). The mean value for spike length $(\mathrm{cm})$ of wheat ranges from 9.30 to $13.18 \mathrm{~cm}$, respectively. The phenotypic coefficient of variance and genotypic coefficient of variance for spike length $(\mathrm{cm})$ was $11.51 \%$ and $4.62 \%$ respectively. The broad-sense heritability percentage for spike length was calculated $7.2 \%$ and the genetic advance percentage was $10.94 \%$ (Table II). In our data, the heritability estimates were observed low along with low genetic advance as observed by Nabi et al. (1998) and Jedynski (2001) in their experiments among some polygenic traits in hexaploid (6n) spring wheat. Moderate heritability with low genetic advance has been reported for spike length by (M et al., 2004).

The spikelet per spike is an important yield enhancing trait because increased spikelets will increase number of grains and eventually grain yield will be increased. Also found same lower values of (PCV) and (GCV) in number of spikelets per spike. The mean square analysis of variance showed significant difference for spikelets per spike (Table I). The mean value for Spikelet per spike of wheat ranges from 14.23 to 24.34 . The phenotypic coefficient of variance and genotypic coefficient of variance for spikelet spike ${ }^{-1}$ was $10.71 \%$ and $9.38 \%$ respectively. The broad-sense heritability percentage for spikelet spike ${ }^{-1}$ was $76.65 \%$ and the genetic advance mean was $20.12 \%$ (Table II). The broad sense heritability of spikelet per spike is high which means this trait is more heritable. High heritability along with moderate value of genetic advance was also reported by (Ali et al., 2008; Mahmood and Chowdhry, 2000; Sharma and Garg, 2002) in wheat for spikelet per spike which are like our result.

Number of tillers per plant is a yield related trait, as it is directly related with number of spikes plant ${ }^{1}$. Thus, greater number of tillers per plant will ensure greater grain yield (Firouzian et al., 2003). Mean square analysis of variance for tillers per plant showed significant difference (Table I). The mean value for total tillers of wheat ranges from 4.4 to 11.5 . The phenotypic coefficient of variance and genotypic coefficient of variance for the total number of tillers was $20 \%$ and $18.09 \%$ respectively. The broad-sense heritability for the total number of tillers was calculated $81.77 \%$ and the genetic advance mean value is $10.75 \%$ (Table II). The broad sense heritability of tillers per plant is high which means this trait is more heritable. Addisu and Shumet (2015) observed similar results in Barley (Hordeum vulgare L.). High heritability and low genetic advance for tillers per plant and grains per spike is seen in the present data but Ajmal et al. (2009) observed high heritability and moderate genetic advance in wheat. Sardana et al. (2007) suggested that high heritability may not necessarily lead to increased genetic gain unless sufficient genetic variability existed in the germplasm.

The mean square analysis of variance showed significant difference for fertile tillers. Mean value for fertile tillers of wheat ranges from 6.2 to 13.4. Maximum numbers of fertile tillers were recoded 13.4 and a minimum of 6.2. The phenotypic coefficient of variance and genotypic coefficient of variance for fertile tillers were $35.43 \%$ and $20.18 \%$ respectively. The broad-sense heritability for fertile tillers was calculated $32.43 \%$ and the genetic advance value in percentage is $7.25 \%$ (Table II). For fertile tillers, low broad sense heritability estimate along with moderate genetic advance was observed, indicating that it is controlled by non-additive gene action. The broad sense heritability of fertile tillers is $32.43 \%$ which means this trait is less heritable. Assefa et al. (2000) observed 23\% heritability estimates for tillers per plant.

Grain yield per plant is a character of chief importance and of special interest to a wheat breeder. Higher estimates for heritability, genetic gain and variability would be important to a wheat breeder to choose promising cross combinations and to attain the maximum level of yield potential. Mean square analysis of variance showed significant difference for grain yield per plant. The mean value for grain yield per plant ranges from $4.31 \mathrm{~g}$ to 20.26 g. The phenotypic coefficient of variance and genotypic coefficient of variance for total seed weight were 35.03\% and $17.17 \%$ respectively. The broad sense heritability in percentage is calculated $24.01 \%$ and genetic advance mean percentage value was calculated 9.81\% (Table II). Kahrizi et al. (2010) reported low heritability estimates for grain yield. Ijaz et al. (2013) reported high heritability and genetic advance for number of tillers per plant and grain yield per plant. 
Hundred seed weight is another principal component of grain yield in wheat. Genotypes showed highly significant difference for hundred seed weight. The mean value for 100 seed weight $(\mathrm{g})$ of weight ranges from 3.06 to 5.19 $\mathrm{g}$. The phenotypic coefficient of variance and genotypic coefficient of variance for total seed weight was $15.39 \%$ and $7.85 \%$ respectively. Broad sense heritability percentage for 100 seed weight is calculated 25.97 and the genetic advance in percentage was $33.48 \%$ (Table II). High broad sense heritability along with moderate genetic advance was reported by (Farshadfar et al., 2013).

Grain yield per spike is a major component of yield and have significant contribution to grain yield. Highly significant differences were observed from mean square analysis of variance for all genotypes (Table I). The mean value for the total yield/spike $(\mathrm{g})$ of wheat ranges from $0.50 \mathrm{~g}$ to $2.27 \mathrm{~g}$. The phenotypic coefficient of variance and genotypic coefficient of variance values for total seed weight was $43.84 \%$ and $39.81 \%$ respectively. Broad sense heritability for total yield/spike (g) was estimated 82.49 and the genetic advance percentage was $73.10 \%$ (Table II). For grain yield per spike other researchers also reported high heritability estimates like (Baloch et al., 2016; Kumar et al., 2012).

The phenotypic correlation of different parameters is shown in the (Table III). The yield and related traits express different trend of relationship among themselves.

There is a positively and significantly association between plant height, spike length (0.4073), Spikelet per spike (0.3685), tiller per plant (0.1129), fertile tiller per plant (0.1129), grain yield per spike (0.1558), and a negative association was found with hundred seed weight (-0.1007). Grain yield per spike was non significantly associated with plant height (0.1558). Similarly, spike length was found positively and significantly associated with spikelet per spike (0.1252), tillers per plant (0.1947), fertile tiller per plant (0.1063). There is non-significant association of spike length was present between grain yield per spike (-0.0035), hundred seed weight (0.0123), and grain yield per spike (0.0691).

Spikelet per spike was found significantly correlated with grain yield per plant (0.1199), and grain yield per spike (0.1097), but a non-significant association was found with tillers per plant (0.0137) fertile tillers per plant (0.0053), and hundred seed weight (0.0345). Tillers per plant was found significantly correlated with fertile tillers per plant (0.5056). Grain yield per plant (-0.0137), hundred seed weight $(0.0457)$ and grain yield per spike (0.0302) was found non significantly associated to tillers per plant. Fertile tillers per plant was found significantly associated with grain yield per plant (0.0699), hundred seed weight (0.1754), and non-significant correlation with grain yield per spike (0.0568). Grain yield per plant was found associated with hundred seed weight (0.1561) and grain yield per spike (0.3587). Hundred seed weight was found significantly correlated with grain yield per spike (0.1102). Positive association of yield grains per spike and 1000-grain weight was observed by (Iftikhar et al., 2013). Positive correlation between 1000 grain weight and plant height in barely was observed by (Hadjichristodoulou, 1990). These findings were reported by (Efisue et al., 2014) in rice (Oryza sativa L.). The number of fertile tillers are positively and non-significantly correlated with total yield per plant. Ali et al. (2008) observed a positive association between grain yield and productive tillers per plant in wheat.

\section{Conclusion}

The results of the study showed that for all the traits the genotypes differed significantly. Heritability values were observed high for all the traits while genetic advance was observed low to moderate, which is an indicator that nonadditive gene action was controlling the expressions of these characters. So, selection is suggested to be delayed to later segregating generations. Furthermore, phenotypic correlation revealed positive correlation of grain yield with plant height, spikelet per spike, and fertile tillers suggesting that more importance should be given to these traits for improving the yield in wheat.

\section{Acknowledgements}

Authors are thankful to Institute of Pure and Applied Biology for providing facilities for experimentation and analysis.

\section{Author's contribution}

Conceptualization of research (SA, HRA); Designing of the experiments (SA, HRA, ZUZ); Contribution of experimental materials (SA, SSQ, AT); Execution of field/ lab experiments and data collection (SA, MJ, ZUZ, MA, SSQ AT); Analysis of data and interpretation (SA, HRA, MA); Preparation of the manuscript (SA, MJ, HRA). 


\section{Declaration}

The authors declare no conflict of interest.

\section{References}

1. Addisu F and T Shumet. 2015. Variability, heritability and genetic advance for some yield and yield related traits in barley (Hordeum vulgare L.) landraces in Ethiopia. International Journal of Plant Breeding and Genetics 9: 68-76.

2. Ajmal SU, N Zakir and MY Mujahid. 2009. Estimation of genetic parameters and character association in wheat. Journal of Agriculture biology and Science 1: 15-18.

3. Akhtar N and M Chowdhary. 2006. Estimation of genetic and phenotypic correlation coefficients among grain yield and its components in bread wheat. International Journal of Agricultural Biology 8: 516-522.

4. Akram T, SR Naqvi, SA Haider and M Kamran. 2017. Towards real-time crops surveillance for disease classification: exploiting parallelism in computer vision. Computers and Electrical Engineering 59: 15-26.

5. Ali F, S Ahmad, J Ali, MA Tunio, MS Afridi and T Iqbal. 2017. Heritability estimates and traits association in wheat advanced lines. International Multidisciplinary Research Journal 13-17.

6. Ali Y, BM Atta, J Akhter, P Monneveux and Z Lateef. 2008. Genetic variability, association and diversity studies in wheat (Triticum aestivum L.) germplasm. Pakistan Journal of Botany 40: 2087-2097.

7. Amin M, M Hasan, N Barma, M Rahman and M Hasan. 2015. Variability and heritability analysis in spring wheat (Triticum aestivum L.) Genotypes. Bangladesh Journal of Agricultural Research 40: 435-450.

8. Assefa K, S Ketema, H Tefera, T Kefyalew and F Chundera. 2000. Trait diversity, heritability and genetic advance in selected germplasm lines of tef [Emgmstis tef(Zucc.) Trotter]. Hereditas 133: 29-37.

9. Aycicek M and T Yildirim. 2006. Heritability of yield and some yield components in bread wheat (Triticum aestivum L.) genotypes. Bangladesh Journal of Botany 35: 17-22.

10. Baloch MJ, GM Channa, WA Jatoi, AW Baloch, IH Rind, MA Arain and AA Keerio. 2016. Genetic characterization in $5 \times 5$ diallel crosses for yield traits in bread wheat. Sarhad Journal of Agriculture 32: 127-133.

11. Bose LK, S Das, SK Pradhan, H Subudhi, S Singh and O Singh. 2007. Genetic variability of quality characters and grain yield in lowland rice genotypes of Eastern India. Korean Journal of Breeding Science 39: 1-6.

12. Dwivedi A, I Pawar, M Shashi and S Madan. 2002. Studies on variability parameters and character association among yield and quality attributing traits in wheat. Haryana Agricultural University Journal of Research 32: 77-80.

13. Efisue AA, BC Umunna and JA Orluchukwu. 2014. Effects of yield components on yield potential of some lowland rice (Oyza sativa L.) in coastal region of Southern Nigeria. Journal of Plant Breeding and Crop Science 6: 119-127.

14. Falconer DS. 1996. "Introduction to quantitative genetics," Pearson Education India.

15. Fao F. 2008. Food and agriculture organisation of the United Nations.

16. Farshadfar E, F Rafiee and H Hasheminasab. 2013. Evaluation of genetic parameters of agronomic and morpho-physiological indicators of drought tolerance in bread wheat (Triticum aestivum L.) using diallel mating design. Australian Journal of Crop Science 7: 268-275.

17. Firouzian A, AS Khan and Z Ali. 2003. Genetic variability and inheritance of grain yield and its components in wheat. Pakistan Journal of Agricultural Sciences 40: 176-179.

18. Gao Z, Y Wang, G Tian, Y Zhao, C Li, Q Cao, R Han, Z Shi and M He. 2020. Plant height and its relationship with yield in wheat under different irrigation regime. Irrigation Science 38: 365-371.

19. Gianessi LP. 2014. Importance of Pesticides for Growing Wheat in South Asia. CropLife Foundation, International Pesticide Benefit Case Study 106

20. Hadjichristodoulou A. 1990. Stability of 1000-grain weight and its relation with other traits of barley in dry areas. Euphytica 51: 11-17. 
21. Haider SA, SR Naqvi, T Akram, GA Umar, A Shahzad, MR Sial, S Khaliq and M Kamran. 2019. LSTM neural network based forecasting model for wheat production in Pakistan. Agronomy 9: 72.

22. Hassan G and R Gul. 2006. Evaluation of the heterotic and heterobeltiotic potential of wheat genotypes for improved yield. Pakisan Journal of Botany 38: 1159-1167.

23. Iftikhar R, SB Hussain and I Khaliq. 2013. Study of inheritance for grain yield and related traits in bread wheat (Triticum aestivum L.). SABRAO Journal of Breeding and Genetics 45.

24. Ijaz F, I Khaliq, MT Shahzad and B Saleem. 2013. Computation of heritability of yield and some morphological traits in F2 populations of spring wheat (Triticum aestivum L). International Journal of Modern Agriculture 2: 102-107.

25. Jamil A, S Khan, OU Sayal, M Waqas, QUllah and S Ali. 2017. Genetic variability, broad sense heritability and genetic advance studies in bread wheat (Triticum aestivum L.) germplasm. Pure and Applied Biology (PAB) 6: 538-543.

26. Jedynski S. 2001. Heritability and path coefficient analysis of yield components in spring wheat. Biuletyn Instytutu Hodowli I Aklimatyzacji Roslin: 203-210.

27. Jockovi M, S Joci, R Marinkovi, S Prodanovi, $\mathrm{P}$ anak, $\mathrm{M}$ iri and $\mathrm{P}$ Mitrovi. 2013. Heritability of plant height and head diameter in sunflower (Helianthus annuus L.). Ratarstvo i povrtarstvo 50: 62-66.

28. Johnson HW, H Robinson and R Comstock. 1955. Estimates of genetic and environmental variability in soybeans 1. Agronomy Journal 47: 314-318.

29. Kahrizi D, K Cheghamirza, M Kakaei, R Mohammadi and A Ebadi. 2010. Heritability and genetic gain of some morpho-physiological variables of durum wheat (Triticum turgidum var. durum). African Journal of Biotechnology 9: 4687-4691.

30. Kamboj R. 2003. Skewness, Heritability and genetic advance in two F2 populations of Bread Wheat. Madras Agricultural Journal 90: 456-460.
31. Karim D, U Sarkar, M Siddique, MK Miah and M Hasnat. 2007. Variability and genetic parameter analysis in aromatic rice. International Journal of Sustainable Crop Production 2: 15-18.

32. Kashif M and I Khaliq. 2004. Heritability, Correlation and Path Coefficient Analysis for Some Metric Traits in Wheat. International Journal of Agriculture and Biology 6(1): 138-142.

33. Khan F, M Khan, G Ghuttai, F Mohammad, W Khan, F Khan and Z Zafar. 2015. Genotypic Differences and Heritability for Various Polygenic Traits in F5 Wheat Populations. American Journal of Environmental Sciences 15: 2039-2044.

34. Khan $\mathrm{N}$ and F Naqvi. 2011. Heritability of morphological traits in bread wheat advanced lines under irrigated and non-irrigated conditions. Asian Journal of Agricultural Sciences 3: 215-222.

35. Kumar A, A Sirohi and S Kumar. 2012. Studies of selection parameter in common bread wheat (Triticum aestivum L.). International Journal of Engineering Science Research 2: 90-94.

36. Kumar B, CM Singh and KK Jaiswal. 2013. Genetic variability, association and diversity studies in bread wheat (Triticum aestivum L.). The Bioscan 8: 143-147.

37. Kumar D and S Kerkhi. 2015. Genetic variability, heritability and genetic advance for yield component and quality traits in spring wheat (Triticum aestivum L.). The Bioscan 10: 2125-2129.

38. Kumar S, G Sandhu, SS Yadav, V Pandey, O Prakash, A Verma, SC Bhardwaj, R Chatrath and GP Singh. 2019. Agro-morphological and Molecular Assessment of Advanced Wheat Breeding Lines for Grain Yield, Quality and Rust Resistance. Journal of Cereal Research 11(2): 131-139.

39. Lu P, H Huang, Q Liu and M Gu. 1991. Heritability and usefulness of traits of Tibetan Wheat varieties. Crop Genetic Resources 1: 11-13.

40. M S-u-H, M M, M Mujahid, K N.S, Z Akram and A Nazeer. 2004. Genetic Analysis of Some Biometric Characters in Bread Wheat (Triticum aestivum L.). Journal of Biological Sciences

41. Mahmood N and M Chowdhry. 2000. Genetic Performance of Bread Wheat Genotypes for Spike 
Parameters Under Normal and Late Planting. Pakistan Journal of Biological Sciences 3.

42. Majumder D, A Shamsuddin, M Kabir and L Hassan. 2008. Genetic variability, correlated response and path analysis of yield and yield contributing traits of spring wheat. Journal of the Bangladesh Agricultural University 6: 227-234.

43. Nabi T, M Chowdhry, K Aziz and W Bhutta. 1998. Interrelationship among some polygenic traits in hexaploid spring wheat (Triticum aestivum L.). Pakistan Journal of Biological Sciences (Pakistan) 1(4): 299-302.

44. Okuyama LA, LC Federizzi and JF Barbosa Neto. 2005. Plant traits to complement selection based on yield components in wheat. Ciencia Rural 35: 1010-1018.

45. Razia R. 2003. Genetic Analysis for yield and yield components in spring wheat under drought conditions. Thesis: University of Agriculture. Pakistan.

46. Sachan M and S Singh. 2003. Genetics of yield and its components in durum wheat (Triticum durum Desf.). Journal of Interacademicia 7: 140-143.

47. Sardana S, R Mahajan, N Gautam and B Ram. 2007. Genetic variability in pea (Pisum sativum L.) germplasm for utilization. SABRAO Journal of Breeding and Genetics 39: 31-41.
48. Shahid M, F Mohammad and M Tahir. 2002. Path coefficient analysis in wheat. Sarhad Journal of Agriculture 18: 383-388.

49. Sharma A and D Garg. 2002. Genetic variability in wheat (Triticum aestivum L.) crosses under different normal and saline environments. Annals of Agricultural Research 23: 497-499.

50. Sial M. 2007. Genetic heritability for grain yield and its related characters in spring wheat (Triticum aestivum L.). Pakistan Journal of Botany 39: 1503-1509.

51. Steel RG and JH Torrie. 1980. Principles and Procedures of Statistics McGraw-Hill Book Co. Inc., New York 481.

52. Tabinda A and DN Bharadwaj. 2015. Study of genetic divergence in wheat (Triticum aestivum L.). Agricultural Communications 3: 1-6.

53. Waqar-Ul-Haq M Malik, M Rashid, M Munir and Z Akram. 2008. Evaluation and estimation of heritability and genetic advancement for yield related attributes in wheat lines. Pakistan Journal of Botany 40: 1699-1702.

54. Wing EAs and D Finance. 2015. Economic Sur. Economic Survey 16. 